\title{
Bakers' Yeast Catalyzed Synthesis of Benzimidazole and Quinoxaline Derivatives in Water
}

\author{
YAHYA S. BEHESHTIHA, MAJID M. HERAVI*, MARYAM AMROLLAH, \\ MINA SAEEDI* and AKRAM FALLAH
}

Department of Chemistry, School of Sciences, Alzahra University, PO Box 1993891176, Vanak, Tehran, Iran

saeedi.mina@gmail.com

Received 7 May 2012 / Accepted 17 May 2012

\begin{abstract}
Bakers' yeast efficiently catalyzes synthesis of the benzimidazole and quinoxaline derivatives in aqueous media, via reaction of 1,2-phenylenediamine derivatives with aromatic aldehyde and 1,2-diketones respectively. The reactions proceed rapidly and the products are obtained through a facile and green procedure in good yields.
\end{abstract}

Keywords: Bakers’ yeast, Benzimidazole derivatives, Quinoxaline derivatives, $N$-Containing heterocycles

\section{Introduction}

$\mathrm{N}$-Containing heterocycles exhibit important and valuable biological activities ${ }^{1}$. Among these various compounds, heterocycles such as benzimidazole and quinoxaline derivatives which contain two heteroatoms are well documented in the literature to exhibit a wide range of biological activities ${ }^{2}$. Benzimidazole derivatives have received considerable attention in recent times because of their applications as antiulcers, antihypertensives, antivirals, antifungals, anticancers and antihistamines among others ${ }^{3}$. In addition, they are important intermediates in many organic reactions ${ }^{4}$ and act as ligands to transition metals for modeling biological systems ${ }^{5}$. Also they have been developed as a series of FXa inhibitors ${ }^{6}$. Recently much attention has been directed towards the synthesis of quinoxalines due to the wide range of biological activity associated with them. For instance, they have been employed in antibiotic structures such as echinomycin, leromycin and actinomycin ${ }^{7}$. Consequently, several methods for the synthesis of benzimidazole and quinoxaline derivatives have been developed during the last few years.

Synthesis of benzimidazoles mainly is based on condensation of 1,2-diaminoarene derivatives with carboxylic acid derivatives ${ }^{8}$, aldehydes ${ }^{9}$, aryl halides ${ }^{10}$ and orthoesters ${ }^{11}$. The most common method for the synthesis of quinoxalines is reaction of 1,2-diaminoarene derivatives with 1,2-dicarbonyl compounds in different conditions. Recently, various protocols have been introduced which achieve this goal efficiently ${ }^{9 \mathrm{~g}, 12}$.

The application of biocatalysis to organic synthesis has attracted much attention ${ }^{13}$. Among microorganisms, bakers' yeast (Saccharomyces cerevisiae) is a well known and preferred catalyst. It is inexpensive, easy to use and its growth does not require the assistance 
of a microbiologist ${ }^{14}$. The application of bakers' yeast in organic synthesis has been proved efficiently. It can catalyze synthesis of polyhydroquinoline derivatives via an unsymmetrical Hantzsch reaction ${ }^{15}$, synthesis of benzothiazoles ${ }^{16}$, oxidative coupling of thiols to disulfides ${ }^{17}$ and stereoselective reduction of $\beta$-keto esters ${ }^{18}$.

In continuation of our efforts to develop new methods in the synthesis of heterocycles containing nitrogen ${ }^{12 a-d, 19}$ herein, we wish to report a facile and green method of obtaining benzimidazole and quinoxaline derivatives. However, to the best of our knowledge, there have not been reports about the synthesis of benzimidazole and quinoxaline derivatives catalyzed by bakers' yeast. Accordingly, treatment 1,2-phenylenediamine derivatives 1 with aromatic aldehyde $\mathbf{2}$ and also 1,2-phenylenediamine derivatives $\mathbf{1}$ with 1,2-diketones in the presence of bakers' yeast resulted in the formation of corresponding benzimidazole and quinoxaline derivatives $\mathbf{3}$ and $\mathbf{4}$ in good yields (Schemes 1 and 2).

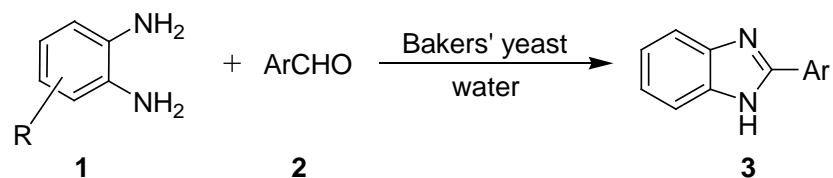

Scheme 1. Bakers' yeast catalyzed synthesis of benzimidazole derivatives.

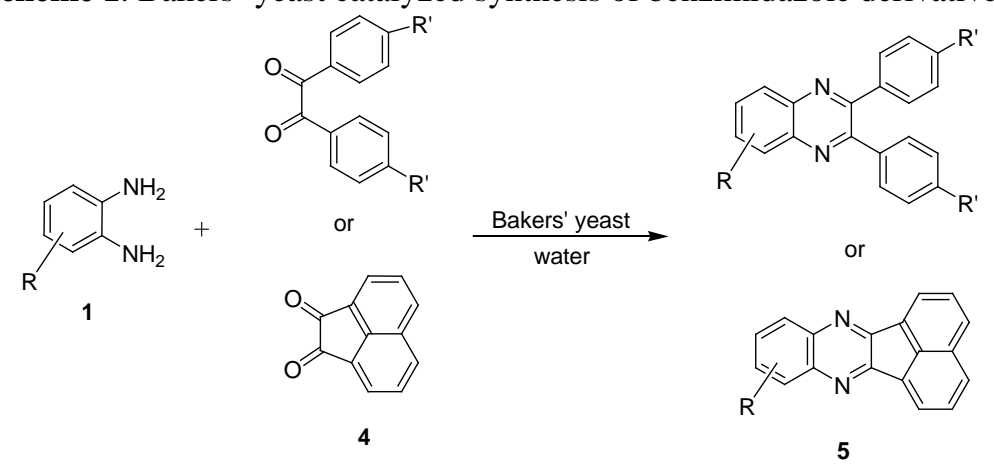

Scheme 2. Bakers' yeast catalyzed synthesis of quinoxaline derivatives.

\section{Experimental}

Bakers' yeast $(0.4 \mathrm{~g})$ was taken in $5 \mathrm{~mL}$ distilled water and stirred overnight. An appropriate aromatic aldehyde (1 mmol) and 1,2-phenylenediamine derivative (1 mmol) were added to the yeast and the reaction mixture was stirred for indicated time in Table 1 . The progress of the reaction was monitored by thin layer chromatography, using petroleum ether/ethyl acetate $(6: 1)$ as a solvent system. After completion of reaction, the mixture was treated with $\mathrm{CH}_{2} \mathrm{Cl}_{2}(5 \mathrm{~mL})$ and filtered off. The product was extracted and the organic layer was dried with $\mathrm{MgSO}_{4}$, filtered and the solvent was removed under vacuum. The pure benzimidazole derivatives were obtained by crystallization from ethanol.

\section{Typical procedure for the synthesis of quinoxalines}

Bakers' yeast ( $0.4 \mathrm{~g})$ was taken in $5 \mathrm{~mL}$ distilled water and stirred overnight. 1,2-diketones (1 mmol) and 1,2-phenylenediamine derivatives $(1 \mathrm{mmol})$ were added to the yeast and the reaction mixture was stirred for indicated time in Table 2 . The progress of the reaction was monitored by thin layer chromatography, using petroleum ether/ethyl acetate (4:1) as a solvent system. After completion of reaction, the mixture was treated with $\mathrm{CH}_{2} \mathrm{Cl}_{2}(5 \mathrm{~mL})$ 
and filtered off. The product was extracted and the organic layer was dried with $\mathrm{MgSO}_{4}$, filtered and the solvent was removed under vacuum. The pure quinoxaline derivatives were obtained by crystallization from ethanol. All compounds were known and their physical data were compared with those of authentic compounds and found to be identical.

\section{Selected spectra data}

2-p-Tolyl-1H-benzo[d]imidazole (3f)

Mp 273-275 ${ }^{\circ} \mathrm{C}$; IR (KBr, $\left.\mathrm{cm}^{-1}\right)$ : 3063, 1523, 1444, 1357, 973, 746; ${ }^{1} \mathrm{H}$ NMR spectrum $\left(500 \mathrm{MHz}, \mathrm{DMSO}-d_{6}\right): \delta=12.81(\mathrm{~s}, 1 \mathrm{H}, \mathrm{NH}), 7.17-8.07$ (ArH, 8H), 2.38 (s, 3H); MS, $\mathrm{m} / \mathrm{z}$ : 208 (M, 100\%).

\section{2,3-Diphenylquinoxaline (5a)}

Mp 124-125 ${ }^{\circ} \mathrm{C}$; IR (KBr, $\left.\mathrm{cm}^{-1}\right): 1664,1591,1473 ;{ }^{1} \mathrm{H}$ NMR $\left(500 \mathrm{MHz}, \mathrm{CDCl}_{3}\right): \delta=7.30-$ 8.23 (m, 14H); MS, m/z: 282 (M, 100\%).

\section{Results and Discussion}

Bakers' yeast $(0.4 \mathrm{~g})$ was taken in $5 \mathrm{~mL}$ distilled water and stirred overnight. 1,2-phenylenediamine $(1 \mathrm{mmol})$ and 4-nitrobenzaldehyde $(1 \mathrm{mmol})$ were added. The reaction mixture stirred for $5 \mathrm{~h}$ at room temperature, followed by workup yielded the corresponding product (3g) in $85 \%$ yield. Under identical conditions, the reaction also proceeds effectively when 1,2-phenylenediamine $(1 \mathrm{mmol})$ is reacted with benzyl (1 mmol) and the corresponding quinoxaline derivative (5a) was isolated in $85 \%$ yield after $10 \mathrm{~min}$. In order to study the catalytic efficiency of bakers' yeast, the model reactions were achieved in the absence of catalyst and in this condition poor yields were resulted. It was found that $0.4 \mathrm{~g}$ of bakers' yeast was enough to give the highest yield. In order to expand the scope of the present work, various aromatic aldehydes and 1,2-phenylenediamine derivatives were examined and corresponding products were obtained. The results are summarized in Table 1.

Table 1. Synthesis of the benzimidazole derivaties catalyzed by bakers' yeast

\begin{tabular}{|c|c|c|c|c|c|c|c|}
\hline Entry & $\mathrm{R}$ & $\mathrm{R}^{\prime}$ & product & Time, h & Yield, $\%^{\mathrm{a}}$ & \multicolumn{2}{|c|}{$\begin{array}{c}\text { m.p. }\left({ }^{\circ} \mathrm{C}\right) \text { Found } \\
\text { Reported }\end{array}$} \\
\hline 1 & $\mathrm{H}$ & $\mathrm{C}_{6} \mathrm{H}_{5}$ & $3 a$ & 4.5 & 85 & $287-289$ & $289-290^{9 b}$ \\
\hline 2 & $\mathrm{H}$ & $4-\mathrm{Cl}-\mathrm{C}_{6} \mathrm{H}_{4}$ & $3 \mathbf{b}$ & 5 & 80 & $283-285$ & $284-286^{9 b}$ \\
\hline 3 & $\mathrm{H}$ & $3-\mathrm{NO}_{2}-\mathrm{C}_{6} \mathrm{H}_{4}$ & $3 c$ & 5 & 82 & $145-146$ & $144^{9 c}$ \\
\hline 4 & $\mathrm{H}$ & $4-\mathrm{Br}-\mathrm{C}_{6} \mathrm{H}_{4}$ & 3d & 5 & 79 & 293-295 & $294-296^{9 h}$ \\
\hline 5 & $\mathrm{H}$ & $4-\mathrm{F}-\mathrm{C}_{6} \mathrm{H}_{4}$ & $3 \mathbf{e}$ & 6 & 82 & $241-243$ & $242-245^{9 h}$ \\
\hline 6 & $\mathrm{H}$ & 4-Me- $\mathrm{C}_{6} \mathrm{H}_{4}$ & $3 f$ & 5 & 80 & $273-275$ & $275^{9 \mathrm{c}}$ \\
\hline 7 & $\mathrm{H}$ & $4-\mathrm{NO}_{2}-\mathrm{C}_{6} \mathrm{H}_{4}$ & $3 g$ & 5 & 85 & 300 & $307-309^{9 h}$ \\
\hline 8 & $\mathrm{H}$ & $3-\mathrm{Br}-\mathrm{C}_{6} \mathrm{H}_{4}$ & $3 \mathrm{~h}$ & 5 & 70 & $263-265$ & $264^{9 \mathrm{e}}$ \\
\hline 9 & $\mathrm{H}$ & 1-Naphthyl & $3 \mathbf{i}$ & 5 & 85 & $265-267$ & $264-265^{9 d}$ \\
\hline 10 & $4-\mathrm{NO}_{2}$ & $4-\mathrm{Cl}-\mathrm{C}_{6} \mathrm{H}_{5}$ & $3 \mathbf{j}$ & 6 & 75 & $280-282$ & $277-281^{9 h}$ \\
\hline 11 & 4-Me & $\mathrm{C}_{6} \mathrm{H}_{5}$ & $3 \mathbf{k}$ & 5.5 & 80 & $244-246$ & $244-246^{9 g}$ \\
\hline 12 & $4-\mathrm{NO}_{2}$ & $4-\mathrm{NO}_{2} \mathrm{C}_{6} \mathrm{H}_{4}$ & 31 & 8 & 70 & $221-224$ & $222-224^{9 \mathrm{~h}}$ \\
\hline 13 & $4-\mathrm{NO}_{2}$ & $p-\mathrm{MeC}_{6} \mathrm{H}_{4}$ & $3 \mathrm{~m}$ & 8 & 75 & $210-212$ & $211-214^{9 h}$ \\
\hline
\end{tabular}

${ }^{a}$ The GC-MS analysis indicated yields 
Aromatic aldehydes carrying either electron-donating or electron-withdrawing substituents reacted efficiently to give the corresponding products in good yields. Using the optimized reaction conditions, we next investigated the aliphatic aldehydes, unfortunately, the expected products could not be obtained. Another model reaction was carried out by taking a 1:2 molar ratio mixture of 1,2-phenylenediamine and 4-nitroaldehyde in the presence of bakers' yeast to obtain 1,2-disubstituted bezimimidazole derivatives. The major product was 2-(4-nitrophenyl)- $1 H$-benzo[d]imidazole and corresponding 1,2-disubstituted bezimimidazole derivative was observed in low yield.

To evaluate the scope and limitations of bakers' yeast various phenylenediamine derivatives and 1,2-diketones were examined and related quinoxaline derivatives were obtained in good yields and very short reaction time. Other derivatives and related data have been tabulated in Table 2.

Table 2. Synthesis of the quinoxaline derivaties catalyzed by bakers' yeast

\begin{tabular}{cccccccc}
\hline Entry & $\mathrm{R}$ & $\begin{array}{c}\text { dicarbonyl } \\
\text { compound }\end{array}$ & product & $\begin{array}{c}\text { Time, } \\
\text { min }\end{array}$ & $\begin{array}{c}\text { Yield, } \\
\%^{\mathrm{a}}\end{array}$ & $\begin{array}{c}\text { m.p., }{ }^{\circ} \mathrm{C} \\
\text { Found } \\
\text { Reported }\end{array}$ & Entry \\
\hline 1 & $\mathrm{H}$ & benzil & $\mathbf{5 a}$ & 10 & 85 & $124-125$ & 1 \\
2 & $4-\mathrm{NO}_{2}$ & benzil & $\mathbf{5 b}$ & 15 & 75 & $193-195$ & 2 \\
3 & $4-\mathrm{Me}$ & benzil & $\mathbf{5 c}$ & 15 & 79 & $114-115$ & 3 \\
4 & $\mathrm{H}$ & $4,4^{\prime}$-dimethoxybenzil & $\mathbf{5 d}$ & 20 & 75 & $149-150$ & 4 \\
5 & $4-\mathrm{Me}$ & $4,4^{\prime}$-dimethoxybenzil & $\mathbf{5 e}$ & 20 & 75 & $129-130$ & 5 \\
6 & $4-\mathrm{Cl}$ & benzil & $\mathbf{5 f}$ & 15 & 75 & $114-115$ & 6 \\
7 & $\mathrm{H}$ & acenaphthenequinone & $\mathbf{5 g}$ & 15 & 89 & $241-242$ & 7 \\
8 & $4-\mathrm{Me}$ & acenaphthenequinone & $\mathbf{5 h}$ & 15 & 80 & 305 & 8 \\
\hline
\end{tabular}

\section{Conclusion}

${ }^{a}$ The GC-MS analysis indicated yields

In conclusion, we have successfully developed an easy, efficient and green method for the synthesis of benzimidazole and quinoxaline derivatives, respectively from the environmentally friendly reaction of 1,2-diaminoarene derivatives with aldehydes and 1,2-diaminoarene with 1,2-dicarbonyl compounds catalyzed by bakers' yeast at room temperature in water. The protocol does not require the use of toxic and expensive catalysts.

\section{Acknowledgment}

We gratefully acknowledge the partial financial support from Alzahra University Research Council.

\section{References}

$1 \quad$ Gillchrist T L, Heterocycl Chem., 1997.

2 (a) Tebbe M J, Spitzer W A, Victor F, Miller S C, Lee C C, Sattelberg T R, Mckinney E and Tang C J, J Med Chem., 1997, 40, 3937; (b) Porcari A R, Devivar R V, Kucera L S, Drach J C and Townsend L B, J Med Chem., 1998, 41, 1252; (c) Roth M, Morningstar M L, Boyer P L, Hughes S H, Bukheit R W and Michejda C J, J Med Chem., 1997, 40, 4199; (d) Corona P, Carta A, Loriga M, Vitale G and Paglietti G, Eur J Med Chem., 2009, 44, 1579; (e) Wagle S, Adhikari A V and Kumari N S, Eur J Med Chem., 2009, 44, 1135. 
3 (a) Erhardt P W, J Med Chem., 1987, 30, 231. (b) Gravalt G L, Baguley B C, Wilson W R and Denny W A, J Med Chem., 1994, 37, 4338. (c) Soderlind K J, Gorodetsky B, Singh A K, Bachur N, Miller G G and Loun J W, Anti-Cancer Drug Des., 1999, 14, 19; (d) Kim J S, Gatto B, Yu C, Liu A, Liu L F and LaVoie E J, J Med Chem., 1996, 39, 992.

4 (a) Bai Y, Lu J, Shi Z and Yang B, Synlett., 2001, 544; (b) Hasegawa E, Yoneoka A, Suzuki K, Kato T, Kitazume T and Yangi K, Tetrahedron, 1999, 55, 12957.

5 (a) Bouwman E, Driessen W L and Reedjik J, Coord Chem Rev., 1990, 104, 143;

(b) Pujar M A and Bharamgoudar T D, Transition Met Chem., 1988, 13, 423.

6 Zhao Z, Arnaiz D O, Griedel B, Sakata S, Dallas J L, Whitlow M, Trinh L, Post J, Liang A, Morrissey M M and Shaw K J, Bioorg Med Chem Lett., 2000, 10, 963.

7 (a) Dell A, William D H, Morris H R, Smith G A, Feeney J and Roberts G C K, J Am Chem Soc., 1975, 97, 2497; (b) Bailly C, Echepare S, Gago F and Waring M, AntiCancer Drug Des., 1999, 15, 291.

8 (a) Dudd L M, Venardou E, Garcia-Verdugo E, Licence P, Blake A J, Wilson C and Poliakoff M, Green Chem., 2003, 5, 187; (b) Niknam K and Fatehi-Raviz A, J Iran Chem Soc., 2007, 4, 438.

9 (a) Nagawade R and Shinde D B, Chin Chem Lett., 2006, 17, 453; (b) Han X, Ma H and Wang Y, Russ J Org Chem., 2008, 44, 863; (c) Khan A T, Parvin T and Choudhury L H, Synth Commun., 2009, 39, 2339; (d) Chakrabarty M, Mukherjee R, Karmakar S and Harigaya Y, Monatsh Chem., 2007, 138, 1279; (e) Saha D, Saha A and Ranu B C, Green Chem., 2009, 11, 733; (f) Giri B Y, Devi B L A P, Lakshmi KV, Prasad R B N, Synth Commun., 2007, 37, 2331; (g) Raju B C, Theja N D and Kumar A, Synth Commun., 2009, 39, 175; (h) Rostamizadeh S, Aryan R, Ghaieni H R and Amani A M, J Heterocycl Chem., 2009, 46, 74.

10 Perry R J and Wilson B D, J Org Chem., 1993, 58, 7016.

11 Mohammadpoor-Baltork I, Moghadam M, Tangestaninejad S, Mirkhani V, Zolfigol M A and Hojati S F, J Iran Chem Soc., 2008, 5, S65.

12 (a) Heravi M M, Bakhtiari K, Tehrani M H, Javadi N M and Oskooie H A, Arkivoc, 2006, 16; (b) Heravi M M, Taheri S, Bakhtiari K and Oskooie H A, Catal Commun., 2007, 8, 211; (c) Heravi M M, Bakhtiari K, Oskooie H A and Taheri S, Heteroatom Chem., 2008, 19, 218; (d) Heravi M M, Tehrani M H, Bakhtiari K and Oskooie H A, Catal Commun., 2007, 8, 1341; (e) Darabi H R, Mohandessi S, Aghapoor K and Mohsenzadeh F, Catal Commun., 2007, 8, 389; (f) Zemin W and Nicholas J E, Tetrahedron Lett., 2001, 42, 8115; (g) Bhosale R S, Sarda S R, Ardhapure S S, Jadhav W N, Bhusareb S R and Pawara R P, Tetrahedron Lett., 2005, 46, 7183; (h) Zhao Z, Wisnoski D D, Wolkenberg S E, Leister W H, Wang Y and Lindsley C W, Tetrahedron Lett., 2004, 45, 4873; (i) More S V, Sastry M N V, Wang C C and Yao C F, Tetrahedron Lett., 2005, 46, 6345; (j) Hasaninejad A, Zare A, Zolfigol M A and Shekouhy M, Synth Commun., 2009, 39, 569.

13 Santaniello E, Ferraboschi P, Grisenti P and Manzocchi A, Chem Rev., 1992, 92, 1071.

14 (a) Servi S, Synthesis, 1990, 1. (b) Jones J B, Tetrahedron, 1986, 42, 3351.

15 Kumar A and Maurya R A, Tetrahedron Lett., 2007, 48, 3887.

16 Pratap U R, Mali J R, Jawale D V and Mane R A Tetrahedron Lett., 2009, 50, 1352.

17 Rao K R and Kumar H M S, Bioorg Med Chem Lett., 1991, 1, 507.

18 Rodri'guez S, Kayser M and Stewart J D, Org Lett., 1999, 1, 1153.

19 (a) Heravi M M, Sadjadi S, Haj N M, Oskooie H A and Hekmat Shoar R, Tetrahedron Lett., 2009, 50, 943; (b) Heravi M M, Baghernejad B and Oskooie H A, Tetrahedron Lett., 2009, 50, 767; (c) Heravi M M, Baghernejad B, Oskooie H A and Hekmatshoar R, Tetrahedron Lett., 2008, 49, 6101. 